\title{
Obraz v velikem planu in pripovedna transparentnost
}

\section{Barbara Zorman}

Univerza na Primorskem, Pedagoška fakulteta, Cankarjeva ulica 5, 6000 Koper, Slovenija https://orcid.org/0000-0003-3498-6958

barbara.zorman@pef.upr.si

Vprvem delu prispevka primerjam različne teoretske poglede na funkcije obraza v filmskem velikem planu. Balázs meni, da spričo povečave prikazanega obraza, ki vzbuja občutek intenzivne bližine, nastane premik v naraciji iz dogajalnega gibanja v mikrogibanje. Deleuze izpostavi veliki plan kot entiteto (ločeno od prostorsko-časounih koordinat, iz katerih izhaja), kjer obrazni izraz postane nosilec afekta, obenem pa obraz izgubi funkcije individualizacije, socializacije in komunikacije, ki so ga predhodno opredeljevale. Barthes piše o obrazu filmske zvezde v vlogi maske, Greco pa o vplivu pogleda, ki ga maska iz ekrana usmerja $v$ gledalca. Plantinga analizira vlogo obraza $v$ "prizorih empatije". V drugem delu članka analiziram film Roka Bička Razredni sovražnik (2013). Netransparentnost obraza se izraža najočitneje pri reprezentaciji lika Sabine, ki sošolce pretrese s samomorom. Nedostopnost Sabinine subjektivnosti predstavljajo bližnji prikazi njenega obraza v kontekstu spominskih predstav njene prijateljice in maske, ustvarjene po fotografiji Sabininega obraza, ki si jih nadenejo njeni sošolci. Sabinin obraz je slepa pega filmske pripovedi; čeprav se pred nami razkriva scela, je njegov pomen odprt, nedoumljiv. Eden od učinkov takega prikaza je zavrnitev obraza kot »znakovnega instrumenta "(Eleftheriotis) oziroma kot transparentne površine, hkrati pa tudi zavrnitev prisvajanja oziroma redukcije skrivnostne drugosti obrazov bližnjih na berljive emocije oziroma afekte.

Ključne besede: filmska teorija / kognitivna znanost / naratologija / obraz v filmu / filmski liki / slovenski film / maska / Biček, Rok 
Vsaka pegica je bila kakor zvezda in imel je vse. Veliki voz, Mali voz, Oriona, Medveda, Dvojčka, Betelgezo, Rimsko cesto. Na njegovem obrazu je bila vsaka zvezda v pravilnem položaju.

Bellow, Herzog 282

There's no art / To find the mind's construction in the face.

Shakespeare, Macbeth, 1. dejanje, 4. prizor

Obrazi, predstavljeni v filmu, nudijo gledalcem poleg svoje osnovne, identifikacijske funkcije vsaj dve vrsti užitka. Po eni strani gre za estetsko kontemplacijo njihove lepote ali unikatnosti. Milton Brener meni, da je obraz lep prav zaradi svoje spremenljivosti, saj nenehno proizvaja izraze, med katerimi nekateri trajajo le petindvajsetinko sekunde. Najpogostejši med izrazi je smehljaj, ki ga znanstveniki kategorizirajo na štiri najpogostejše različice, čeprav so, kot meni Brener, njegove nianse skoraj neskončne (35). Iain McGilchrist piše, da se hoteni oziroma prisiljeni obrazni izrazi manifestirajo večinoma $\mathrm{v}$ okolici ust, bolj pretanjeni in nehoteni čustveni izrazi pa v zgornji polovici obraza (59). Za gledalce so torej obrazi zapeljivi tudi zaradi želje po prisvajanju njihovih pomenov, ta pa izhaja iz domneve, da jih je mogoče prebrati, dešifrirati. V medosebni komunikaciji interpretiramo, z obrazom zrcalimo in si včasih preko čustvene nalezljivosti celo prisvojimo obrazne izraze in občutja oseb, $s$ katerimi smo v stiku. A vendar nam obrazi drugih, zlasti neznancev, v resničnem življenju najpogosteje predstavljajo skrivnost, saj iz njih ne zmoremo razbrati dejanskih občutij in misli; obrazne izraze zlahka interpretiramo $\mathrm{v}$ neskladju z dejanskim občutjem njegovega nosilca.

Filmi pogosto prikazujejo konflikte, ki izvirajo iz tovrstnih nesporazumov. Po drugi strani pa je gledalcu v odnosu do protagonista dovoljena izredno velika mera vpogleda v notranja stanja; možnost zaupanja, zaupnosti med prejemnikom in fikcijskim likom je eden ključnih užitkov fikcije. Kadar nam fikcija vzbuja občutek, da je drugi »berljiv«, se to dogaja preko tako imenovane "transparentne pripovedi«, kjer nam podatke posreduje zanesljiva pripoved oziroma fokalizacija. Film ima mnogo tehnik, s katerimi omogoči vpogled v subjektivnost drugega, npr. glasbo, pripovedni kontekst, govor, pripoved, ki je podana skozi perspektivo (npr. percepcijsko polje) lika; v angleški filmski terminologiji posnetke, kjer filmska pripoved dogajanje prikazuje iz zornega kota enega od likov, imenujejo point-of-view shot. 
V pričujočem članku me najbolj zanima pripovedna vloga obraza kot transparentne površine, ki gledalcu razkriva subjektivnost predstavljenega lika. Kot ugotavlja Carl Plantinga, so obrazi likov v filmu, posebej tisti, ki nam preko pripovedi ponujajo vživetje $\mathrm{v}$ svoj položaj, pogosto namenoma in izrazito transparentni, toda njegove ugotovitve so vezane večinoma na analizo hollywoodskih filmov. Prizore, ki uporabljajo te vrste izraznost za posredovanje pripovednih podatkov ali spodbujanje določenih odzivov pri gledalcih, imenuje "prizori empatije" (scenes of empathy) (»The Scene" 247). Plantinga meni, da v nasprotju z dejanskimi situacijami, v katerih svoja občutja z obrazi prikrivamo vsaj toliko, kolikor jih razkrivamo, v konvencionalnih filmskih prizorih empatije obraz izraža notranja stanja lika, in sicer tako, da se liki prikažejo v položajih, v katerih v njihovi obrazni izrazi ne bodo dojeti kot zavajajoči, temveč nam bodo iskreno posredovali občutja na primer ko je čustvujoči lik prikazan takrat, ko meni, da ga nihče ne opazuje (251). V nasprotju s tovrstno transparentnostjo protagonistov klasične hollywoodske narativnosti je $\mathrm{v}$ tradiciji evropskega filmskega modernizma oziroma novih valov razmerje med gledalcem in zaslonom drugačno, saj je naracija teh filmov pogosto avtorefleksivna, opozarja torej na svojo umetniško zgradbo, konstrukcijo. Thomas Elsaesser in Malte Hagener ugotavljata, da nam tovrstne pripovedi vzbujajo občutek, da je »zatopljenost v fikcijo nemogoča». Ta naravnanost ustreza stališču psihoanalitične filmske teorije, ki gledanje filma dojema kot proces zavajajoče identifikacije, kot gledanje v zrcalo lažnega samospoznavanja (72-73). Tako kognitivna kot psihoanalitična filmska teorija bosta predstavljeni $\mathrm{v}$ prvem delu prispevka, ki primerja različne teoretske poglede na obraz $\mathrm{v}$ velikem planu. $\mathrm{V}$ drugem delu prispevka pa bo vloga obraza predstavljena z analizo filmskega prvenca Roka Bička Razredni souražnik (2013).

\section{Obraz v velikem planu kot okno v dušo}

Béla Balázs je bil madžarski filmski scenarist in režiser, ki je zaslovel kot filmski kritik, posebej z zbirko esejev Der sichtbare Mensch: oder Die Kultur des Films (1924), v kateri je med prvimi pisal o izraznosti obraza $\mathrm{v}$ filmu v povezavi z estetiko nemih filmov.

Balázs je bil prepričan, da je obrazni izraz najbolj subjektivna manifestacija človeškega. Polifonično in ambivalentno naravo emocije naj bi obrazna mimika predstavila ustrezneje kot besede. Zapisal je, da je veliki plan izumil nov nejezikovni medij oziroma komunikacijski kod 
med subjektivnostjo lika in gledalca, in sicer s pomočjo dolgo pozabljenega univerzalnega jezika kretenj in obraznih izrazov. Za Balázsa je obraz v velikem planu zaznamovan $\mathrm{z}$ dvojnostjo: obraz igralca je površina, na kateri se prikaže subjektivnost lika. Meni, da v nasprotju z odrskim, gledališkim igralcem, ki predstavlja svojo vlogo prek mnoštva mask, ki si jih nadeva za potrebe predstav, filmski igralec »živi notranja stanja lika", sicer dojemamo njegov izraz kot lažen. Povečani posnetek dovoli gledalčevemu pogledu tako blizu prikazanega obraza, piše Balázs, da bi pri potvarjanju, prikazovanju nepristnega čustva določeni deli obraza nehote izdali emocije, ki "so v nasprotju s prevladujočim obraznim izrazom" (Theory 77). Za Balázsa obraz v velikem planu ni nikoli netransparenten:

[V]idimo, da je tam nekaj, česar ne moremo videti. Beremo med vrsticami. [...] to so mikrofizionomije velikega plana, ki so nam dale najbolj pretanjeno igro obraznih potez, skoraj nezaznavno, a vendar tako prepričljivo. Tako se je izza vidnega obraza pojavil nevidni obraz, ki je viden eni osebi, tisti, ki jo naslavlja - in občinstvu. ${ }^{1}(77)$

Balázs torej verjame v »nevidno«, skrito obličje, ki se manifestira preko obraza v velikem planu zaradi novih tehnoloških možnosti kinematografije: povečave prikazanih objektov. Tako se gledalčeva pozornost usmeri $v$ fragment naracije:

Veliki plan je tehnični pogoj umetnosti obraznega izražanja in s tem visoke filmske umetnosti sploh. Obraz moramo približati in ga ločiti od vsakršnega okolja, ki bi nas lahko zmotilo [...] tako dolgo si ga moramo dovoliti opazovati, da ga res lahko beremo. Film zahteva pretanjenost in zanesljivost mimike, o kakršni igralec, ki nastopa zgolj na odru, ne more niti sanjati. (Der sichtbare 48)

Balázs poudarja, da veliki plan zaznamuje prostorsko-časovna ločenost od diegeze. Pripovedni tok je suspendiran, zamrznjen, a ne zato, da bi pripoved prešla na navajanje atributov kakega objekta, kot v literarnem opisu, temveč zaradi prestopa na gibanje drugačne vrste. Povečano gibanje obraznih potez, piše Balázs, izgubi povezavo s pripovednim prostorom in "prikažejo se emocije, razpoloženja, nameni in misli, stvari, ki jih oči lahko vidijo, čeprav niso v prostoru« (Theory 61).

Balázsove ugotovitve so $\mathrm{v}$ nasprotju $\mathrm{z}$ domnevo, da na gledalčeve predstave o občutjih $\mathrm{v}$ filmu predstavljenega lika bolj kot izraz na obrazu vplivajo montažni postopki. To stališče je na podlagi eksperi-

${ }^{1}$ Ta in ostali prevodi iz tujejezičnih virov so delo Barbare Zorman. 
menta Leva Kulešova, izvedenega v Rusiji v začetku preteklega stoletja, v delu Film Technique and Film Acting predstavil V. I. Pudovkin. Kulešov je isti posnetek obraza (ki ga Pudovkin opisuje kot statičnega in neekspresivnega) znamenitega ruskega igralca nemih filmov, Ivana Možuhina, v montažnem zaporedju postavil ob posnetek juhe, trupla, igrajočega se otroka. Občinstvo, ki si je ogledalo posnetke, je bilo navdušeno, piše Pudovkin, nad igralsko ekspresivnostjo Možuhina. Hvalili so zamišljenost ob pozabljenem krožniku juhe, globoko žalost, ki jo je izražal njegov obraz ob pogledu na umrlo žensko in veselje ob pogledu na igrajoče se dekletce. Pudovkin opisani učinek razlaga tudi z dolžino posnetkov; podobno kot $\mathrm{v}$ glasbi tudi $\mathrm{v}$ filmu ritem vpliva na občutja gledalca; hitri in kratki posnetki povzročajo vznemirjenje, dolgi in počasni pa imajo pomirjujoč učinek (140-141).

Kontrast med Balázsevim in Pudovkinovim pogledom na funkcijo obraza v velikem planu izpostavlja najstarejšo in najvplivnejšo dihotomijo $\mathrm{v}$ teoretskih pogledih na film, in sicer razlikovanje med formalističnimi in realističnimi pristopi (Elsaesser in Hagener, Teorija 13). Eisenstein film razume v okvirjih formalističnih teorij, ki film analizirajo predvsem preko njegove konstrukcije in kompozicije, Balázs pa pripada drugi struji, ki poudarja (delno) transparentnost filma oziroma njegovo sposobnost, da nam omogoči nova spoznanja o predstavljeni resničnosti.

\section{Obraz v velikem planu kot entiteta}

Gilles Deleuze se na Balázsa nanaša zlasti v študiji Podoba-gibanje (1983), v poglavjih o podobi-afekciji - ki zanj določa »afektivno branje celotnega filma" (120). Tako kot Balázs Deleuze obrazov ne pripisuje zgolj domeni človeškega, temveč praktično vsakemu aspektu filmskega prostora, ki deluje kot »živčna ploščica, organonosilka[, ki je] žrtvovala bistveni del svoje globalne gibljivosti in ki svobodno sprejema in izraža najraznovrstnejša drobna lokalna gibanja« (121). V velikem planu gre skratka za prostor, ki je izločen iz prostorsko-časovnih koordinat in ki postane reflektirajoča površina oziroma z mikrogibanjem izraža določeno kvaliteto ali potenco (121). Obraza oziroma poobličenih površin ne moremo ločiti od afektov, ki jih izražajo (obrazi pa se med seboj razlikujejo po svojem potencialu za predstavljanje afektov); takšno enoto oziroma entiteto, torej množico afekta in obraza, imenuje Deleuze »ikona" (132). Obraz v velikem planu, izražen kot podoba-afekcija, izgubi funkcije, ki so ga določale v njegovem prejšnjem kontekstu, tj. individualizacijsko, socializacijsko in komunikacijsko. Veliki plan - 
obraz $\mathrm{v}$ podobi-afekciji je tako $\mathrm{v}$ svoji deteritorializaciji odtrgan tudi od svojega nekdanjega nosilca, osebe. Tako si obrazi naposled začnejo postajati podobni, zamenljivi. Deleuze stopnjuje brezosebnost obraza v velikem planu do skrajnosti:

Ni velikega plana obraza. [...] Golota obraza je večja od golote telesa, nečloveškost obraza je večja od nečloveškosti zveri. [...] Poleg tega pa veliki plan naredi iz obraza fantom in ga izroča fantomom. Obraz je vampir in pisma so njegovi netopirji, njegova izrazna sredstva [...]. Obrazi se zlivajo drug v drugega, si sposojajo svoje spomine in se nagibajo k temu, da se med seboj pomešajo. [...] [V] eliki plan-obraz je hkrati obličje in njegov izbris. (135-136)

\section{Obraz v velikem planu kot maska}

Deleuzevo tezo, da so obrazi v velikem planu brezosebni, je mogoče zaslediti že v eseju Rolanda Barthesa o obrazu Grete Garbo, ki je v izšel v zbirki esejev z naslovom Mythologies leta 1957. Deleuze brezosebnost obraza izpeljuje prek koncepta njegove "golote" in zlasti mikrogibanja, ki razgiba obraz $\mathrm{v}$ afektu. Barthes pa pri obravnavi obraza Grete Garbo, zlasti na primer v zadnji sekvenci filma Queen Christina (Rouben Mamoulian, 1933), izhaja iz njegove negibnosti, statičnosti. Obraz Grete Garbo je za Barthesa neprebojen, popoln, božanski. Obraz dive določa tisto, kar ga prekriva; njegov make-up ima "snežno gostoto maske« - to »ni naličen obraz, temveč obraz iz mavca, ki ga varuje površina barve in ne njegove poteze«. Barthes vzpostavi kontrast med varovalno funkcijo maske in samotnostjo oči, „črnih kot pulpa, drhtečih ran«, ki spominjajo na "bolezenske izrastke oči« na totemskem obrazu Charlieja Chaplina. Zapeljivost igralkinega obraza izvira iz absoluta maske, njene božanskosti, skrivnostnosti, nedoumljivosti (94).

V The Face: A Natural History (2000) Daniel McNeill piše o obrazni lakoti (face hunger) - potrebi, da bi videli celoto in podrobnosti obraza ljudi, s katerimi komuniciramo. Maska oziroma skrivanje obraza lahko spodbudi željo gledalcev, da bi videli izraz na obrazu oziroma delu obraza, ki je skrit (155-156). Podobno željo, hrepenenje, pravzaprav obsedenost, opisuje roman Der Man der Greta Garbo liebte, ki ga je J. M. Frank napisal 1933. V študiji »Adoratori romaneschi della Garbo: (de)figurazioni narrative di un volto divino (1933-2007) « Giuseppe Girimonti Greco analizira ta roman, ki predstavlja dogodivščine berlinskega uradnika, družinskega moža po imenu Tobia Müller. Tega naključno kinematografsko srečanje z obrazom Grete Garbo v velikem planu povsem pretrese: zdi se mu, da ga je pogled dive, usmerjen vanj 
iz velikega ekrana, nagovoril. Ta ideja protagonista obsede: obraz Grete Garbo začne srečevati povsod, zdi se mu, da ga zasleduje kot fantom, fantazmatska projekcija imaginarnega (Greco 159), zaradi česar uradnik izgubi stik z realnostjo in zaposlitev, odtuji pa se tudi od žene. Naposled odpotuje v Los Angeles, ker začne igralko iskati. Ko jo naposled zagleda v sončni svetlobi pred filmskim studiem, se Tobia Müller sooči z obrazom, ki je močno naličen, maskiran za potrebe filma, ki je občutljiv na modri spekter svetlobe. Veke in usta igralke, temno modro pobarvane, se razkrijejo na bledi sinje rumenkasti podlagi njene kože. To srečanje, ugotovi Greco, je za protagonista travmatična izkušnja, zaradi katere se fantazmatska projekcija razkroji in za obrazom oziroma masko Dive se razkrije obraz Müllerjeve žene, ki ji je igralka močno podobna (162). Ta tragikomična zgodba o obsesiji aludira na gledalčevo iluzijo prisvajanja (stapljanja z lastnimi fantazijami) povečanih obrazov igralcev, kar se dogaja v kontekstu mitologiziranja zvezd, ki jih ustvarja kinematografska industrija. Tako Barthesov esej kot Frankov roman prikažeta privlačnost zvezdniškega obraza $\mathrm{v}$ velikem planu kot zavajajočo masko. Koncept gledalske identifikacije kot samoprevare ima ključno vlogo tudi v psihoanalitični filmski teoriji.

\section{Obraz v velikem planu kot zrcalo}

Thomas Elsaesser in Malte Hagener v zgodovini teorij o filmu predstavita poglede na film med drugim preko metafor vrat, okna in zrcala. Zadnja metafora, ugotavljata avtorja, označuje samonanašalnost (avtoreferencialnost) modernističnega filma, ki zavrača možnost identifikacije; označuje jo kot prevaro, napačno spoznavanje (misrecognition) (83). Koncept ogledala je zavzemal osrednje mesto v psihoanalitični filmski teoriji. Kot ugotavljata Elsaesser in Hagener, je predstava o filmu kot ogledalu prevladovala v filmski teoriji med 1960 in 1980, posebej v teoriji Christiana Metza, ki je v študiji Le signifiant imaginaire: psychanalyse et cinéma (1977) predstavil film kot »imaginarni nosilec fragmentirane zaznave gledajočega subjekta« (nav. po Elsaesser in Hagener 82-83). Ker gledalčevo telo v filmu nikoli ne najde lastnega odseva, gre za dejanje napačne prepoznave oziroma napačnega spoznanja. Gledalec drugega zmotno prepoznava kot sebe oziroma vidi sebe $\mathrm{v}$ nekom drugem (83). Identifikacijo $s$ pomočjo napačnega spoznanja Metzeva teorija primerja z značilnostmi Lacanovega zrcalnega stadija. Metz razlikuje med primarno identifikacijo $s$ kamero in sekundarno identifikacijo z liki (Elsaesser in Hagener 85-86). 
Kognitivna filmska teorija zavrača psihoanalitično teorijo lažne identifikacije oziroma jo skuša nadomestiti z bolj niansiranimi koncepti. Pri analizi obraza v velikem planu poudarja predvsem njegov intersubjektivni in afektivni potencial; izhaja iz prepričanja, da film gradi na vrojeni človeški sposobnosti soobčutenja afektivnih stanj drugih in nam tako ponuja utelešeno pot do empatije $s$ človeškimi bitji, četudi fikcijskimi. Odkritje funkcij zrcalnih nevronov, ki ljudem omogočajo, da občutijo določeno situacijo, kot bi jo doživeli v telesu druge osebe, je bila ena od temeljnih spodbud kognitivne filmske teorije, ki je v osemdesetih letih prejšnjega stoletja začela raziskovati kognitivne procese filmske recepcije.

Carl Plantinga v članku "The Scene of Empathy and the Human Face on Film « analizira odzivanje gledalcev na emocije likov v prizorih, ki obraze slednjih prikazujejo v velikem planu - te imenuje "prizori empatije« (239). Dejavnike, ki vplivajo na gledalčevo vrednotenje obraza, je mogoče $s$ Plantingo in ostalimi teoretiki povzeti $\mathrm{v}$ petih točkah: a) karizma, zvezdniški status, privlačnost igralcev, ki upodabljajo lik; b) ekspresivnost upodobljenih obrazov - pri tem Plantinga ugotavlja, da je ekspresivnost obraza $\mathrm{v}$ tovrstnih prizorih poudarjena in prikazana transparentno; da gledalcu torej posreduje karseda natančne podatke o notranjem stanju lika (»The Scene« 251). Ekspresivnost obraza v velikem planu ne pomeni teatralične, pretirano patetične obrazne mimike, ki je značilna za igro v nekaterih nemih filmih. Thomas Elsaesser and Malte Hagener ugotavljata, da je eden temeljnih paradoksov, povezanih $\mathrm{z}$ upodabljanjem obraza $\mathrm{v}$ velikem planu, paradoks gibljivosti in neizraznosti. Film namreč izraznost obraza "gradi s pomočjo drastične redukcije njegove gibkosti in gibljivosti, saj se nas v velikem planu dotaknejo že najmanjši, skoraj neopazni gibi obraza« (98); c) podaljšano trajanje prikaza povečanega obraza. Plantinga ugotavlja, da so prizori, ki predstavljajo obraz v ameriških filmih, znatno daljši od drugih prizorov, saj razvoj empatije zahteva trajanje (»The Scene« 250). Poleg trajanja pa je pomemben faktor še povečava oziroma bližina prikazanih obrazov, kot je ugotavljal že Béla Balázs; č) Obrazne reprezentacije delujejo v povezavi s pripovednim kontekstom, ki je najbrž eden najmočnejših dejavnikov vzbujanja empatije. Ta zahteva, kot rečeno, določeno trajanje, zato se prizori empatije navadno pojavijo v zaključku pripovedi (251); d) kulturni kontekst; gledalčev odnos do predstavljenih likov gradi na izkušnjah s fikcijskimi in nefikcijskimi osebami kot tudi na usklajenosti vrednot, ki jih predstavljajo liki, z vrednotami, ki so jih gledalci ponotranjili s socializacijo. 


\section{Razredni sovražnik}

Čeprav je Razredni sovražnik (2013) režijski prvenec Roka Bička, gre za enega najkvalitetnejših dosežkov sodobnega slovenskega filma, kar so med drugim potrdile naklonjene kritike in številne nagrade na filmskih festivalih, npr. na Festivalu slovenskega filma v Portorožu in Mednarodnem filmskem festivalu v Benetkah. Razrednega sovražnika lahko umeščamo v tradicijo »šolskih" filmov, kot sta npr. If.... (Lindsay Anderson, 1968) ali Entre les murs (Laurent Cantet, 2005); ti pogosto tematizirajo nasilje, ki zaznamuje šolski sistem in konflikt med individualno svobodo ter pravili, ki omogočajo gladko skupinsko delovanje. Kot v Entre les murs tudi $\mathrm{v}$ Razrednem sovražniku šola prerašča iz dogajalnega prostora $\mathrm{v}$ neke vrste mikrokozmos, a obenem tudi vodilno tematiko in simbol. Izhod iz šole v Razrednem sovražniku nakaže samo Sabina, in sicer v prizoru, ki simbolizira njen samomor. V zadnji sekvenci, ki kaže dijake na končnem izletu, pa je simbolika šole prikazana z drugačnim označevalcem - ladjo sredi morja. Podobno kot v Entre les murs je tudi v Razrednem sovražniku učitelj lik, ki želi uveljaviti drugačne vzgojne principe od obstoječih, a mu pri tem ne uspe; toda če gre v Entre les murs za željo po demokratizaciji, gre v Razrednem sovražniku za avtoritarnost.

V Razrednem sovražniku se dijaki četrtega letnika stopijo v kolektivnega protagonista. Ta proces okrepita dva dogodka. Dogajanje najprej razgiba prihod novega učitelja, ki kot razrednik in učitelj nemščine zaradi porodniškega dopusta učiteljice Nuše prevzame razred in dijake šokira s svojimi skrajno avtoritarnimi metodami. Ključni sprožilni motiv v naraciji pa je samomor ene dijakinj. Krivdo zanj razred pripiše novemu učitelju, vanj usmeri tudi skrajno jezo, ki se izraža v bojkotiranju, obtoževanju in poniževanju. Zaradi izjemne kvalitete filma in pripovedne tematike, ki jo je moč umestiti v poljubni srednjeevropski kontekst, je Razrednega sovražnika mogoče obravnavati kot enega reprezentativnih primerov sodobnega evropskega filma. Obenem pa je film za osrednjo temo prispevka zanimiv tudi zato, ker subjektivnost likov podaja predvsem prek bližnjih prikazov njihovih obrazov. Ti prikazi v določenih kontekstih, kot bom nakazala kasneje, transparentno podajajo občutja likov, še večkrat pa so obrazi likov zadržani v svoji izraznosti, skrivnostni, večpomenski. Tovrstna filmska reprezentacija, kjer je razumevanje subjektivnosti lika oteženo oziroma upočasnjeno, zaznamuje navezanost na dediščino modernističnega filma, ki pripovedno transparentnost destabilizira $\mathrm{z}$ močno avtorefleksivnostjo, $\mathrm{v}$ kateri se filmska naracija zazira v lastno konstrukcijo. Biček je v intervjuju s 
Špelo Barlič (»Razredni«) kot referenco oziroma navdih navedel filme Michaela Hanekeja, zlasti Caché. Hanekejevi filmi so znani po poudarjeni etični dimenziji. Ta se kaže tudi na ravni režiserjeve premišljene konstrukcije filmske naracije, ki je v določenih elementih bolj kot $\mathrm{v}$ podajanje vsebine usmerjena $\mathrm{v}$ avtorefleksijo lastnih učinkov.

\section{Obrazi kot okna v notranja stanja likov}

Razredni sovražnik $\mathrm{v}$ veliki meri gradi na izraznosti obrazov; ti so prikazani večinoma v velikih oziroma srednjih planih, poleg tega se kamera na obrazih igralcev zadržuje relativno dolgo. Počasni, dolgo trajajoči kadri in pogosto fokusiranje na obraze igralcev so med drugim značilni za evropski modernistični film, denimo za stvaritve Ingmarja Bergmana ali Jean-Luca Godarda. Bližnji posnetki obrazov, kakor sta ugotovila že Balázs in Deleuze, abstrahirajo in prestavijo gibanje iz narativnega toka dogodkov na raven podobe-afekcije. S tem pa filmska pripoved prikazani lik iz/loči iz okolice, ki ga obdaja, predvsem od drugih diegetskih likov, kot tudi iz zgodbenega konteksta. Lik se v bližnjem posnetku obrača vase in se razkriva gledalcu v svoji intimi, ga s tem nagovarja $\mathrm{k}$ zavezništvu. Obenem pa veliki plan tudi izpostavlja samoto, izoliranost lika. Obrazi so pomembni tudi v zgodbeni komunikaciji med liki; v Bičkovem filmu se enako pogosto kot $\mathrm{z}$ besedami sporazumevajo $s$ pogledi. V nekaj prizorih so pogledi, ki jih en lik nameni drugim/ drugemu, izrazito dolgi. Taki so na primer pogledi učitelja Zupana, ki odgovarjajo na obtožbe dijakov (sliki 1 in 2).

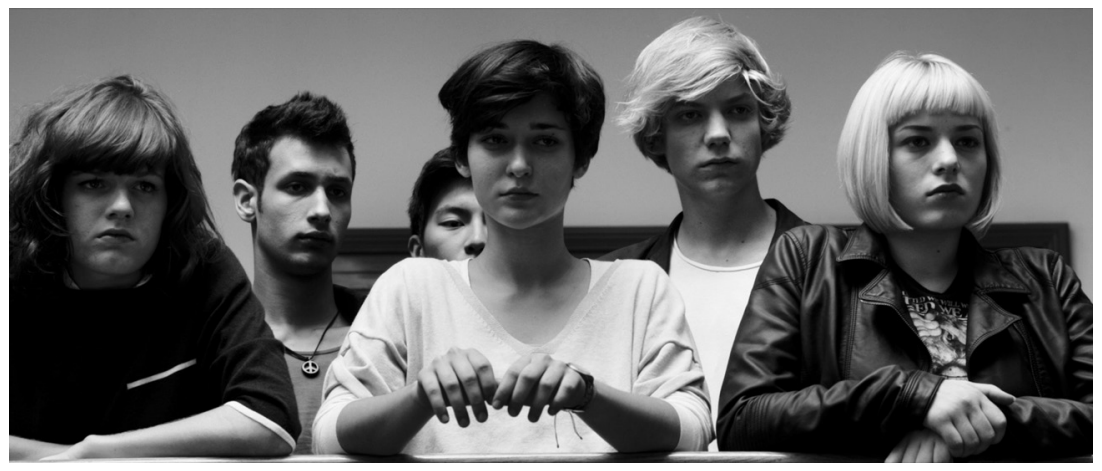

Slika 1: Maruša (Pia Korbar), Luka (Voranc Boh), Chang (Kangjing Qiu), Mojca (Doroteja Madrah), Tadej (Jan Župančič) in Špela (Špela Novak) v Razrednem sovražniku (2013). Copyright Triglav film. 


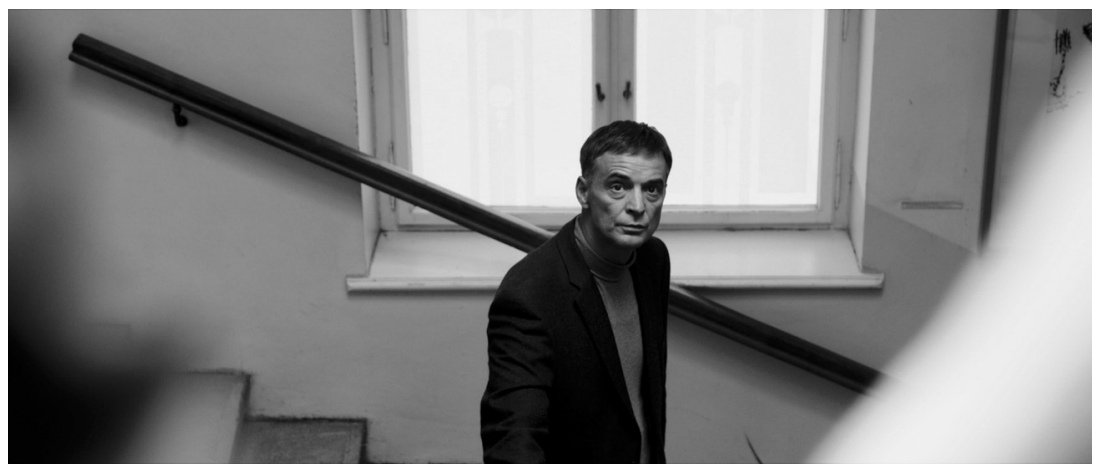

Slika 2: Robert Zupan (Igor Samobor) v Razrednem sovražniku (2013). Copyright Triglav film.

Če pogledi prevzemajo mesto besed, pa se obenem preciznost besed kot $s$ konvencijami določenih označevalcev nadomešča $s$ pomensko ambivalenco in polifonijo pogledov; tak je na primer Sabinin pogled $\mathrm{v}$ Zupana, ko učitelj vstopi v prostor, kjer dekle igra klavir (slika 3).

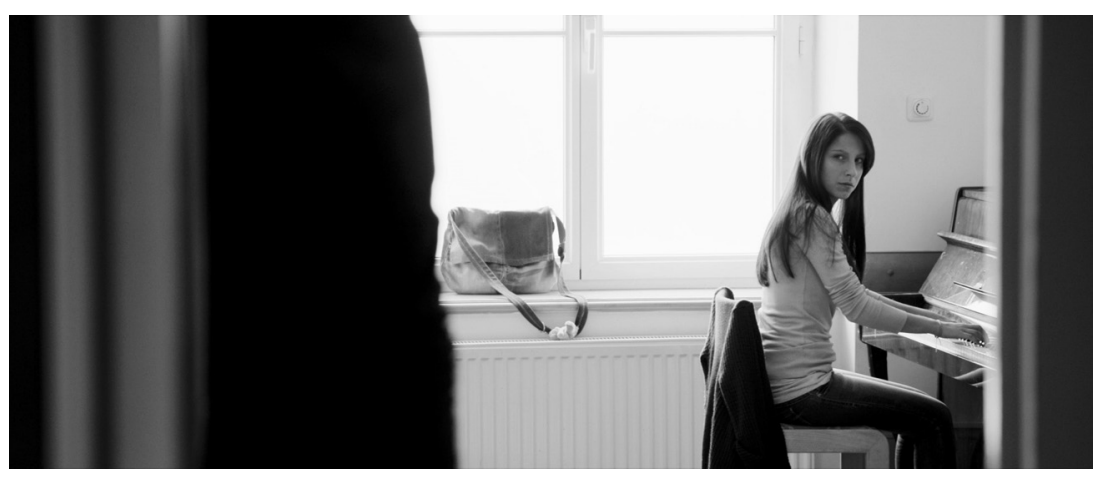

Slika 3: Sabina (Daša Cupevski) in Robert Zupan (Igor Samobor) v Razrednem sovražniku (2013). Copyright Triglav film.

Pomensko preciznejši in bolj transparenten je pogled Maruše, ki se obrnjena s hrbtom proti kameri oddaljuje od gledalčevega pogleda, ko zapušča učilnico, v kateri je videla Zupana, ki je prisostvoval Sabininemu igranju. Maruša se počasi obrne nazaj, ko se ozre proti prostoru, ki ga je zapustila, hkrati pa proti kameri oziroma gledalcem usmeri svoj obraz, pogled. Ta izraža množico čustev, ki jo prevevajo in med katerimi dominirata osuplost in nerazumevanje, morda tudi gnus nad prizorom, ki mu je bila pravkar priča. Temni odtenki njenega obraza pri 
tem ustvarjajo konflikt $s$ svetlobo in belino odtenkov dekletove obleke in globine polja. V opisanem prizoru gre za pripovedno posredovanje čustev in misli gledalcu/-ki, hkrati pa pogled, uprt v kamero, nakazuje avtorefleksivnost pripovedi; Elsaesser in Hagener menita, da oči, uprte iz zaslona $\mathrm{v}$ gledalce, te nujno zdramijo iz zatopljenosti v fikcijo.

Režiser je želel, da bi bila prikazana občutja avtentična oziroma resnična. Zato je v filmu prikazano dogajanje - samomor in razredni upor, ki sta se zgodila na gimnaziji, ki jo je obiskoval - prej natančno raziskal; uporabil je tako pogovore kot osebne spomine. V prikazu avtentičnosti dogajanja je bilo pomembno tudi režijsko delo z igralci naturščiki, ki se je začelo z dolgotrajnim postopkom izbiranja zasedbe. $\mathrm{V}$ intervjuju je Biček povedal, da je bilo njegovo delo z igralci podobno "psihoterapevtski seansi« (v Barlič, "Razredni«). Izvabljanje potlačenih emocij je bilo nemara za nekatere igralce travmatično, vendar je režiser $s$ tem dosegel učinek realizma v ekspresivnosti likov, in sicer ta, da »igralec ne izhaja iz neke vnaprejšnje predstave o liku, da ne igra, temveč živi njegovo življenje« (»Razredni«).

$\mathrm{V}$ uvodni sekvenci nam film kaže čustvena stanja glavnih protagonistov razreda. Najprej dvajset sekund trajajoč srednji-veliki plan prikazuje Sabino, ki tiho in zamišljeno sedi za svojo mizo. Zdi se, da gleda nekaj, kar vidi le sama in ne drugi diegetski liki. Nato petdeset sekund spremljamo tesnobno Mojco in njeno srečanje s fantom Luko, čigar obraz je žalosten, nekako zamrznjen. Kasneje izvemo, da mu je umrla mama. Vzdušje razreda tako določajo žalost, tesnobnost in otopelost, kar predstavljajo Sabina, Mojca in Luka. To vzdušje na avdio-vizualni ravni izražajo prevladujoči beli in sivi barvni odtenki ter Chopinova glasba. Žalobnejša in resnejša čustva $\mathrm{v}$ predstavitvi razreda pa se občasno kontrastno dopolnijo tudi z bolj razposajenimi razpoloženji, ki jih predstavljajo Špela, Nik in Tadej ter ostali manj izpostavljeni člani razreda. Obrazi mladih, ki predstavljajo dijake, temeljijo na mladostniški iskrenosti, ekspresivnosti, čustvenosti, spontanosti. Izrazi njihovih čustev ter afektov so intenzivni in fluidni, hkrati pa preskakujejo, prehajajo med liki, saj so dijaki predstavljeni kot kolektivni protagonist. Ta je blizu predstavi posameznika kot kompleksnega, nestalnega skupka različnih hotenj, interesov, vzgibov, zmožnosti. Po drugi strani pa se tako predstavljeni kolektivni protagonist oddaljuje od klasičnega junaka, ki s svojo motivacijo premočrtno poganja narativno dogajanje. Kot že omenjeno, je kolektivni protagonist poudarjeno labilen in anonimen. Razred se poenoti zgolj $\mathrm{v}$ agresiji in uporu proti učitelju Zupanu. Kolektivni protagonist v tem primeru gledalcu ne omogoča čustvene povezave, vživetja, saj nobeden od obrazov ni prikazan na 
platnu dovolj konsistentno dolgo, da bi lahko gledalec vanj usmeril svojo naklonjenost oziroma empatijo in z napetostjo spremljal, ali bo oseba uresničila svoje želje.

\section{Obraz kot maska}

Zupana je upodobil Igor Samobor, ki je svojo kariero zgradil v osrednjem nacionalnem gledališču in je eden najkredibilnejših in najbolj karizmatičnih slovenskih igralcev. Predstavil je učitelja, ki ima jasne cilje; dijakom želi privzgojiti proaktivno suverenost, ki temelji na disciplini, delu in pridobivanju znanja. Ker je učitelj avtoritativen in jih ne poskuša zapeljati s prijaznostjo, ga dijaki izberejo za grešnega kozla, napadejo ga in ponižujejo. Omenjena dejstva bi gledalcem morala omogočiti čustveno navezano na ta lik. Obenem pa lik Zupana gledalcu ne omogoča, da bi se vživel v njegovo doživljanje, saj je predstavljen kot dosledno racionalna figura, ki nikoli ne pokaže čustev. Tudi v trenutku, ko ga dijaki preko šolskega radia kruto in nepravično obtožujejo in bi se gledalec lahko povezal z njim v njegovi ranljivosti, Zupan ohrani nepremičen obraz, stisnjene ustnice, kameri pokaže hrbet, odide $\mathrm{v}$ razred in za sabo zaloputne vrata. Glavna značilnost novega učitelja je netransparentnost. Robert ostane vse do izteka filmske pripovedi, ki jo zaključi $\mathrm{z}$ dolgim nagovorom, $\mathrm{v}$ katerem dijake opozarja na njihovo labilnost, tako za zgodbene like kot za gledalce tujec. Biček kot eno glavnih značilnosti, ki gledalcu zapirajo dostop do tega lika in hkrati tudi do vrednot, ki jih predstavlja, izpostavi njegovo govorico v nemščini. Zupan, meni Biček, "govori modro, ampak ker govori $v$ nemškem jeziku in $s$ pozicije moči, avtomatično vzbudi v nas nek negativen praspomin" (v Barlič, „Razredni«). S tem je Biček nemara meril tudi na prototipe slovenskega filma (in njegovih navezav na narodno-konstitutivno literaturo), tj. partizanske filme. Te zaznamuje, kot prikaže Peter Stankovič v Rdečih trakovih, študiji reprezentacije v slovenskem partizanskem filmu, manihejska struktura prikaza likov. $\mathrm{Na}$ eni strani so pripadniki nemškega naroda (posebej oficirji), ki jih zaznamuje krutost, racionalnost, mehaničnost (podobni so strojem), odsotnost čustev. Na drugi strani pa imamo tople, človeške, humorne, z naravo povezane Slovence (79). K Zupanovi nedostopnosti, tujosti pa nedvomno prispevajo tudi obrazna mimika, drža, gestikulacija. V prizorih, ko Zupana prvič vidimo pred razredom, sicer deluje nekoliko krhko, na preži, a obenem tudi povsem zadržano, nedostopno. $\mathrm{Na}$ vesel pozdrav ob prvem srečanju, ki se izvije iz razreda, se odzove z minimalnim nasmeškom, da zadosti najosnov- 
nejšim vljudnostnim zahtevam. Gre za prisiljeno gesto; Zupan se na prijaznost ne odzove spontano, temveč ustnice prisili v lažni smehljaj. Njegov obraz je obrambna drža, s katero ohranja distanco, zadržanost, nadrejenost: je konstantno neekspresiven, hladno odvrača poskuse zbližanja tako s strani učencev kot kolegov. Z obrazom nikoli ne zrcali čustev svoje okolice, na druge like se odziva povsem v nasprotju s pričakovanji. V netransparentnosti ga podpira filmska naracija, ki gledalcu ne omogoči vpogleda v Zupanovo preteklost oziroma okolje, iz katere prihaja. Ko si ureja prostor v kabinetu, v rokah za hip ljubeče podrži uokvirjeno podobo, ki pa je gledalcu ni dano videti. V celotnem filmu razen imena, priimka in njegovega poklicnega udejstvovanja o njem ne izvemo ničesar. Prikaz Zupana je omejen na profesionalno izvajanje. Zato deluje kot skrivnost, uganka, zaprta knjiga, kot maska (slika 4).

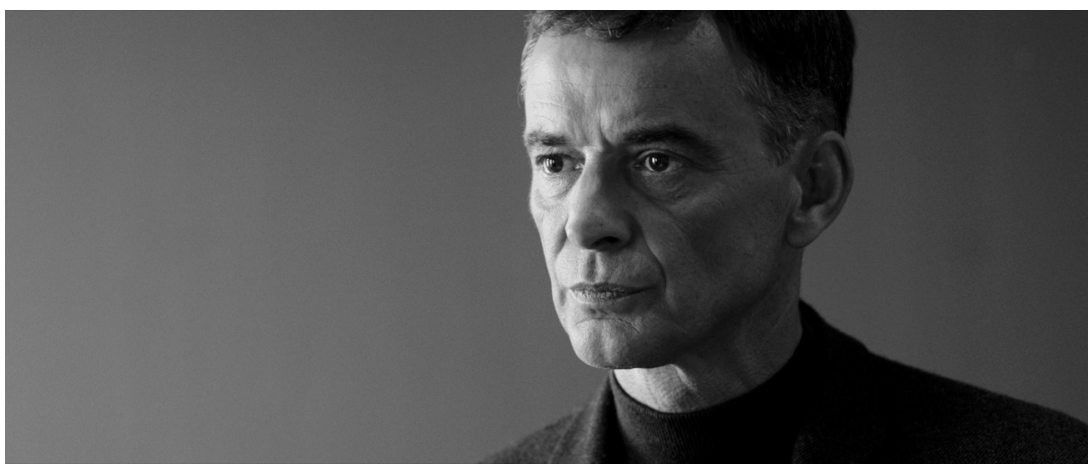

Slika 4: Robert Zupan (Igor Samobor) v Razrednem sovražniku (2013). Copyright Triglav film.

Kljub temu gledalci filma, kot sem se lahko prepričala v pogovorih $s$ številnimi študenti, ki so si film ogledali, ne zavrnejo Zupana kot antijunaka, ki v njih vzbuja le negativna čustva, na primer strah ali jezo. Mnogi gledalci so menili, da so bila Zupanova hotenja in dejanja častna in so se tudi lahko strinjali z njegovim prepričanjem, da šola zahteva večjo mero strogosti in avtoritarnosti. Lik v filmu torej lahko gledalce pripravi do zavezništva s svojimi vrednotami, četudi jim ne dopusti vstopa v svojo subjektivnost in jim z mnogimi dejanji vzbuja antipatijo.

Kot je razumeti iz intervjujev, Bičkov namen ni bil prikaz zgodbe zgolj iz ene perspektive. Pripoved o posledicah samomora sošolke in uporu proti učitelju je želel gledalcem predstaviti kot presečišče, »bojno polje» različnih hotenj, videnj, ne da bi katerega od njih predstavil kot bolj ali manj resničnega, vrednega, pravega (v Barlič, »Razredni «). 
Njegov prikaz likov torej zaznamuje opolnomočenje gledalcev, ki so prisiljeni, da sami ovrednotijo pozicije različnih likov. Največ praznih mest pa je v predstavitvi Sabine, dijakinje, ki je naredila samomor, kar je eno glavnih gibal narativnega dogajanja.

\section{Obraz kot slepa pega pripovedi}

Rok Biček je o liku Sabine izjavil:

Chopin je v svoje kompozicije ujel vse to, kar v sebi nosi lik Sabine. O njej v bistvu vemo zelo malo. Tudi jaz jo poznam le bežno. Sem pa začutil, kaj nosi v sebi, ravno skozi Chopina. Upam, da bo tako tudi pri gledalcih. Nekaterih stvari se enostavno ne da opisati z besedami in takrat je glasba najboljši pomočnik. (Barlič, "Razredni»)

Podobno malo vedo o Sabini njeni sošolci. V nekaj stavkih, ki nakazujejo pogovor o samomoru, sošolci ugotavljajo, da o njej ne vedo pravzaprav ničesar. Mojca, njena najboljša prijateljica, ni bila nikoli pri njej doma. Sabine, ugotavljajo sošolci, niso ne videli, ne slišali.

Menim, da je za razumevanje lika Sabine, kolektivnega lika razreda in temeljnega sporočila filma, ključna sekvenca, v kateri Mojca bere esej o samomoru, naslovljen s citatom Thomasa Manna, ki se v prevodu, navedenem v scenariju Razrednega sovražnika, glasi: »Človekova smrt je bolj zadeva svojcev kakor njega samega." Ta sekvenca se začne s posnetkom, ki od strani in izza hrbta prikazuje Zupanov vstop v razred in njegovo soočenje z dijaki, ki so si obraze pokrili maskami, ustvarjenimi iz fotografije Sabininega obraza. Ko pride do katedra, si Zupan nadene Sabinino masko. Nato pozove Mojco, naj prebere svoj esej. Mojca, ki ji je fant $v$ predhodni sekvenci očital brezčutnost in jo pripravil do joka, pride pred tablo. Sledi kader, v katerem je Mojca v ospredju kadra predstavljena iz profila, tako da je njen obraz deloma prekrit s Sabinino masko. V ozadju kadra pa vidimo Zupana, ki s Sabininim obrazom na maski strmi v kamero. Mojca začne brati esej. Naslednji posnetek Mojco, ki nosi Sabinino masko, prikaže v velikem planu; maska gleda v kamero, v gledalca.

Mojca začne z branjem spisa, v katerem je izrazila svoja občutja ob Sabininem samomoru. Esej tematizira nenehno razmišljanje o umrli prijateljici in vzroku njene smrti; obsesivna vprašanja in občutki krivde se $\mathrm{v}$ tekstu kažejo $s$ kopičenjem paralelizmov in repeticij. Mojčina subjektivnost se vzpostavlja z govorom, nagovarjanjem bližnje osebe, ki se ne more odzvati, na vprašanja ne more odgovoriti. Mojčin govor 
določa potujitveni efekt nemščine, predvsem pa glas, njegov ritem, kadence, zadrževanje joka. Mojčin glas lahko deluje na gledalca preko "prozodičnega zrcaljenja«, ki je po Brenerju pomemben element empatije; višina tona, intonacija, ritem, premolki v gibanju govorčevega glasu lahko na poslušalca vplivajo $s$ skupnim spreminjanjem dihanja in mišičnimi premiki (Brener 31). V tem filmu je sluh bolj empatičen kanal kot vid; najgloblja spoznanja o likih nam ponudijo njihovi glasovi in Chopinova glasba - ti pronicajo v telesa gledalcev in onemogočajo distanco do predstavljenega dogajanja.

Mojčine besede spremljajo prikazi Sabine, ki hodi od garderobnih omaric $\mathrm{v}$ kleti proti razredu $\mathrm{v}$ prvem nadstropju stavbe; njeno vzpenjanje iz teme kleti $\mathrm{k}$ svetlobi je $\mathrm{v}$ navezavi na prizor iz uvodnega dela filma, ki samomor nakaže $s$ prestopom skozi šolska vrata v bleščečo svetlobo. Zaporedje posnetkov, ki prikazujejo Sabinino vzpenjanje po stopnicah, je sestavljeno iz nekaj dolgo trajajočih - najdaljši je dolg 50 sekund - mobilnih velikih planov Sabininega obraza. Interakcija besed in slik implicira, da Sabinin obraz, prikazan v tej sekvenci, lahko interpretiramo kot Mojčino mentalno predstavo, kot vizualno dimenzijo njenega obsesivnega vračanja h ključnemu vprašanju, skrivnosti filma: vzroku Sabininega samomora. Sabinin obraz na Mojčina vprašanja ne odgovori; zazrt je vase, v svoje misli, nedoumljiv. Ključna podoba-afekcija v filmu torej kaže Mojčino mentalno podobo prijateljičinega obraza v obdobju, tik preden si je Sabina vzela življenje. Če Mojčine besede obsesivno ponavljajo vprašanje, zakaj jo/jih je prijateljica zapustila, nam Mojčina miselna predstava Sabininega obraza s svojo zastrtostjo (v kontrastu s klovnovsko obrazno mimiko Špele in Tadeja v ozadju) kaže, da Mojca nagovarja Sabino brez upanja na odgovor.

Še bolj nedoumljiv pa je Sabinin obraz takrat, ko kot maska, izdelana iz fotografije na njeni dijaški vozovnici, nameščena na obrazih njenih sošolcev, zre v gledalca. Pomnoženi, v maski razosebljeni obraz upira v kamero pogled, ki nagovarja gledalce, ne da bi ga mogli razumeti. Sabinin obraz je v obeh primerih, kot Mojčina mentalna predstava in kot maska, manj pomenljiv v tem, kar hoče povedati, kot $\mathrm{v}$ tistem, kar skriva. 


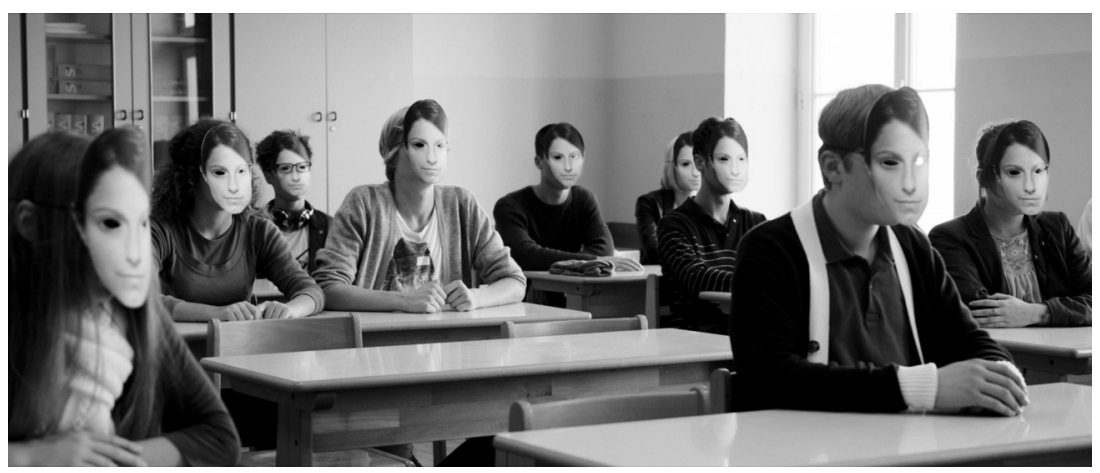

Slika 5: Razred z maskami gleda v učitelja Roberta Zupana v Razrednem sovražniku (2013). Copyright Triglav film.

Če interpretiramo Sabino zgolj v kontekstu šole kot mikrokozmosa, se nam prikaže kot ne zgolj prezrti, temveč tudi izbrisani del kolektiva. Sabina predstavlja tisto, česar skupina ni želela videti, sprejeti kot svojega in se je zato izločilo iz kolektivnega telesa. In vendar se njen obraz nenehno vrača $\mathrm{v}$ vidno polje in tako opozarja na skrito, izbrisano, ki tako postane bistveni, označevalni del skupine. $\mathrm{V}$ prizoru, ko sošolci prekrijejo svoje obraze s Sabininim, je individualnost dijakov reducirana; razred se skrije v kolektivnost oziroma v anonimnost, Sabinin obraz pa mimikrira individualna občutja krivde in sramu v manifestacijo kolektivne agresije (slika 5).

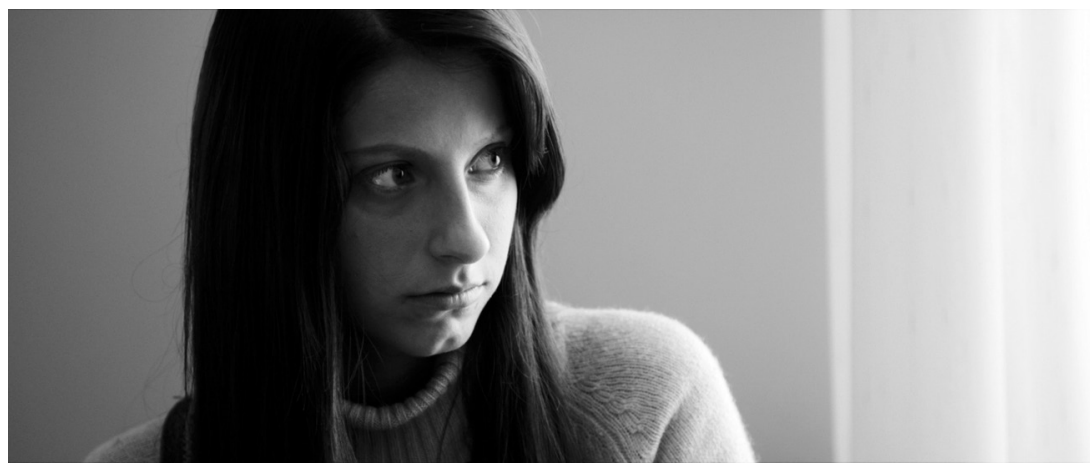

Slika 6: Sabina (Daša Cupevski) posluša učitelja Roberta Zupana, ki jo obtožuje lenobe in pasivnosti v ekspoziciji Razrednega sovražnika (2013). Copyright Triglav film.

Sabinin obraz je slepa pega filmske pripovedi; neprosojno mesto, ki prekriva vzrok, motiv njenega dejanja. V tem smislu Sabinina skriv- 
nostnost predstavlja funkcijo obraza v velikem planu, vsaj kot se kaže v Bičkovem filmu; čeprav se pred nami razkriva scela, je za nas njegov pomen odprt, nedoumljiv. Verjetno je bil motiv za ustvarjalčevo odločitev za uporabo mask drugačen, a eden od učinkov te odločitve je zavrnitev obraza kot "znakovnega instrumenta" (Eleftheriotis 216). V filmu, kjer je ključna sekvenca določena z elementom mask, prikazanih obrazov ni mogoče interpretirati kot transparentnih površin, ki gledalcem iskreno posredujejo afekte, emocije, misli.

Podobno ugotovitev izpelje Dimitris Eleftheriotis iz analize uvodne sekvence Hanekejevega filma Code inconnu (2000), v kateri pantomimičnega prikaza deklice njeni vrstniki nikakor ne morejo interpretirati pravilno. Ta prikaz, obenem z umestitvijo drugih velikih planov v tem filmu po mnenju Eleftheriotisa nakazuje Hanekejevo težnjo po izzivanju "samozadostnosti obraza kot označevalca subjektivnosti drugega». Tovrstna interpretacija obrazne mimike implicira tudi izničenje drugosti in posplošeno razumevanje drugega kot nekoga, ki obstaja izven historičnih in kulturnih specifik (215-216).

Zdi se, da sta se $\mathrm{v}$ predstavitvi različnih teoretskih pogledov na obraz $\mathrm{v}$ velikem planu izrisala vsaj dva različna pogleda na to tematiko. Kognitivna, zlasti anglo-ameriška filmska teorija je v nekaterih aspektih blizu Balázsevemu prepričanju, da film s pomočjo povečav in podaljšanega trajanja prikazov človeških obrazov razvija dovzetnost za komunikacijo s pomočjo obrazne mimike, torej za vlogo ozaveščanja utelešenih občutij pri razvijanju empatije. Po drugi strani pa Gilles Deleuze, kot že omenjeno, izraža prepričanje, da veliki plan obraze, ki postanejo izključno nosilci afektov, razoseblja, pri čemer je ključnega pomena njihova ločenost od konteksta, torej okolja, dogajanja in oseb, ki so njihovi nosilci. Psihoanalitična filmska teorija filmsko recepcijo povezuje s procesom zavajajoče identifikacije, ki jo predstavlja kot gledanje v zrcalo lažnega samospoznavanja (Elsaesser in Hagener 72-73). Modernistični film približani obraz in zlasti pogled, uprt iz ekrana v gledalca, pogosto uporablja za nagovarjanje, zapeljevanje gledalca, obenem pa tudi v kontekstu razbijanja filmske iluzije, preprečevanja zatopljenosti v fikcijo. Navsezadnje, kot je bilo prikazano prej, Dimitris Eleftheriotis izpostavi obraz v velikem planu kot označevalec, ki pokaže afekte in emocije, hkrati pa zabrisuje specifični kulturni oziroma zgodovinski kontekst, ki določa prikazano subjektivnost.

Čeprav Bičkov film uporablja obraze igralcev kot enega najmočnejših kodov za posredovanje občutij in idej, sta ključni obličji te filmske pripovedi netransparentni. Obraza Sabine in Zupana pogosto delujeta kot maski. Zdi se, da tako problematizirata možnost obraza kot označevalca, 
ki se kaže kot okno v človeško psiho, in obenem opozarjata na ambivalentno sporočilnost velikega plana obraza.

\section{LITERATURA}

Balázs, Béla. Der sichtbare Mensch: oder Die Kultur des Films. Frankfurt: Suhrkamp Verlag, 2001. Tudi na spletu. Dostop na naslovu https://epdf.pub/der-sichtbaremensch-oder-die-kultur-des-films.html 22. 1. 2020.

Balázs, Béla. Theory of the Film (Character and Growth of a New Art). Prev. Edith Bone. London: Dennis Dobson Ltd., 1952.

Barlič, Špela. »Razredni sovražnik je vsaj srednjeevropska zgodba«. Intervju z Rokom Bičkom. Pogledi 13. 09. 2013. Tudi na spletu. Dostop 10. 1. 2020.

Barthes, Roland. „Obraz Garbo«. Prev. Polona Poberžnik. Časopis za kritiko znanosti, 31.212 (2003): 94-95. Tudi na spletu. Dostop 12. 1. 2020.

Bellow, Saul. Herzog. Prev. Mira Mihelič. Ljubljana: Delo, 2004.

Brener, Milton E. Evolution and Empathy: The Genetic Factor in the Rise of Humanism. Jefferson, N. C.: McFarland \& Co., 2008.

Deleuze, Gilles. Podoba-gibanje. Prev. Stojan Pelko. Ljubljana: ŠKUC: Znanstveni inštitut Filozofske fakultete, 1991.

Eleftheriotis, Dimitris. „Cosmopolitanism, Empathy and the Close-Up«. The Routledge Companion to Cinema and Politics. Ur. Yannis Tzioumakis in Claire Molloy. London in New York: Routledge, 2016. 209-225.

Elsaesser, Thomas in Hagener, Malte. Teorija filma: uvod skozi čute. Prev. Polona Petek. Ljubljana: Slovenska kinoteka, 2015.

Girimonti Greco, Giuseppe. »'Adoratori' romanzeschi della Garbo: (de)figurazioni narrative di un volto divino (1933-2007)«. L'immagine ripresa in parola: letteratura, cinema e altre visioni. Ur. Matteo Colombi, Stefania Esposito in Massimo Fussilo. Rim: Meltemi, 2008. 145-169.

McGilchrist, Iain. The Master and His Emissary. New Haven in London: Yale University Press, 2012.

McNeill, Daniel. The Face: A Natural History. Boston, New York in London: Little, Brown and Company, 2000.

Mitchell, W. J. Thomas. What do Pictures Want?: The Lives and Loves of Images. Chicago: The University of Chicago Press, 2005.

Plantinga, Carl. "The Scene of Empathy and the Human Face on Film«. Passionate Views: Film, Cognition, and Emotion. Ur. Carl Plantinga in Greg M. Smith. Baltimore: Johns Hopkins University Press, 1999. 239-256.

Plantinga, Carl. "Facing Others: Close-Ups of Faces in Narrative films in The Silence of the Lambs". The Oxford Handbook of Cognitive Literary Studies. Ur. Lisa Zunshine. Oxford; New York: Oxford University Press, 2015. 291 - 312.

Pudovkin, Vsevolod Illarionovich. Film Technique and Film Acting: The Cinema Writings of V. I. Pudovkin. Prevajalec: Montagu, Ivor. London, Vision Press Limited, 1954.

Shakespeare, William. Shakespeare: Complete Works. Ur. W. J. Craig. London: Oxford University Press, 1969.

Stankovič, Peter. Rdeči trakovi: reprezentacija v slovenskem partizanskem filmu. Ljubljana: Fakulteta za družbene vede, 2005. 


\section{FILMOGRAFIJA}

Anderson, Lindsay, in Michael Medwin (producenta). Lindsay Anderson (režiser). If... VB: Memorial Enterprises.

Benjo, Caroline, Carole Scotta in Barbara Letellier (producentke). Laurent Cantet (režiser). Entre les murs. Francija: Haut et Court, 2008.

Heiduschka, Veit, Michael Katz in Margaret Menegoz (producenti). Michael Haneke (režiser). Caché. Francija, Avstrija, Nemčija, Italija: France 3 Cinéma, Canal+, Bavaria Film, Wega Film, 2005.

Karmitz, Marin (producent). Michael Haneke (režiser.) Code inconnu: récit incomplet de divers voyages. Francija, Nemčija, Romunija: Arte France Cinéma, Bavaria Film, Canal+, Filmex, France 2 Cinéma, Les Films Alain Sarde, MK2 Productions, Romanian Culture Ministry, Zweites Deutsches Fernsehen (ZDF), 2000.

Prosenc, Aiken Veronika, in Janez Lapajne (producenta). Rok Biček (režiser). Razredni sovražnik. Slovenija: Triglav film, 2013.

Wanger, Walter (producent). Rouben Mamoulian (režiser). Queen Christina. ZDA: Metro-Goldwyn-Mayer, 1933.

\section{The Face in Close-Up and Narrative Transparency}

Keywords: film theory / cognitive science / narratology / face on film / film characters / Slovenian film / mask / Biček, Rok

In its first part, the article compares various theoretical insights into the topic, beginning with Balázs's claim that the magnification and proximity of the face in close-up replace narrative movement, i.e. action, with micromovement that represents subjectivity. For Deleuze, the face in close-up is deterritorialized into the 'feeling-thing,' the entity as the set-up of the affect. For Deleuze, the close-up abstracts the face from its bearer. Furthermore, the film face as a mask is presented (Barthes). Besides the metaphor of the cinema as a mirror within psychoanalytical film theory, the insights of the cognitive film theory are analyzed, particularly the function of the face in the "scenes of empathy" (Plantinga). The second part examines the role of the face in Rok Biček's first feature film Razredni sovražnik (Class Enemy, 2013), which presents the revolt of a class against an authoritative teacher following the suicide of their classmate Sabina. This film exposes the opaqueness of the face most notably in the representation of Sabina's face, particularly as it is presented within the context of her friend's mental images, memories. But the mysteriousness of her face is most prominent in the masks created from the photography of Sabina's face that her classmates put on in an act of rebellion against their teacher. 
Sabina's face is the film's blind spot: although completely exposed to our gaze, its meaning remains ambiguous, even unattainable. Such representation seems to reject the face as "an instrument of signification" (Eleftheriotis).

1.01 Izvirni znanstveni članek / Original scientific article UDK 791.2:572.54

791.229.2(497.4)Biček R.

DOI: https://doi.org/10.3986/pkn.v43.i1.04 